
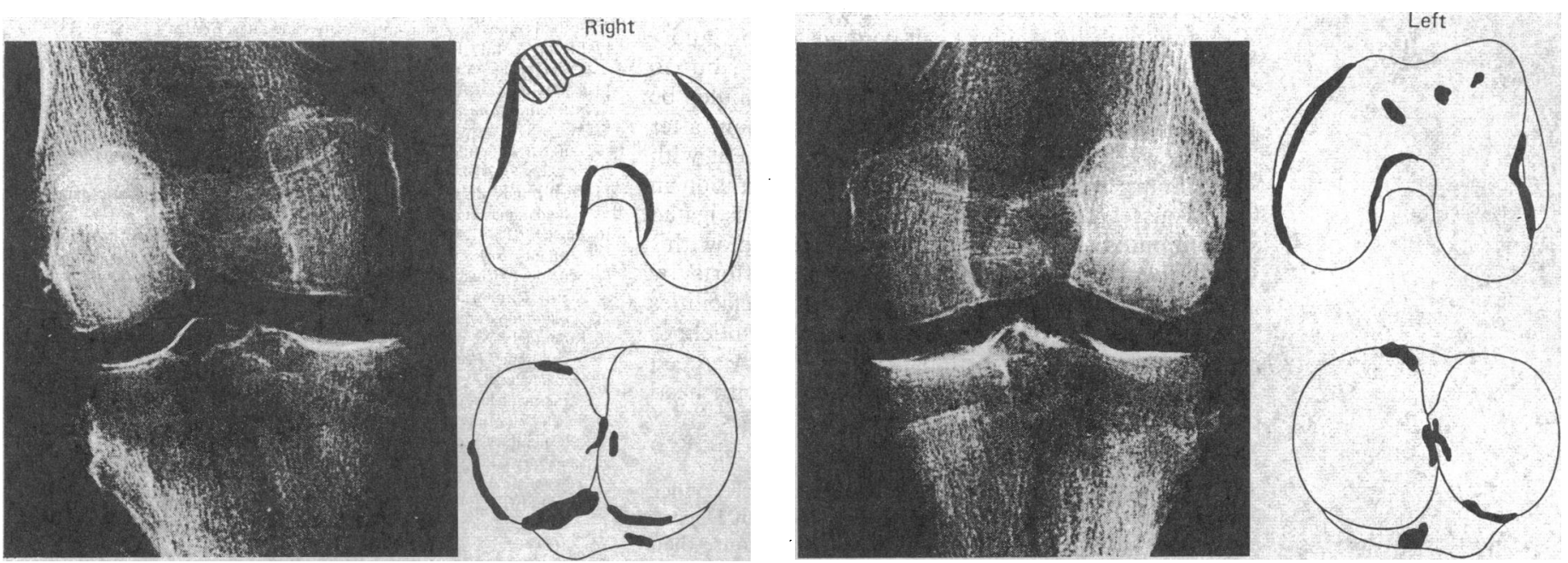

Comparison of radiograph and visual assessment of one pair of knee joints, showing extensive eburnation (hatched area) and severe osteophytosis (solid lines) Radiograph appears normal and $x$ ray findings was striking. Severe osteophytosis and eburnation were often not visible in $x$ ray films even when these were re-examined with hindsight.

The frequency with which osteoarthritis is reported in archaeological material and current figures for the prevalence of the disease ${ }^{3}$ are often compared. The different sensitivity of the methods used to make a diagnosis, shown by this study, and the fact that palaeopathologists often equate osteophytosis with osteoarthritis ${ }^{4}$ make such a comparison misleading. In our study 11 of 24 knee joints had osteophytes alone and a further five had other visual changes compatible with osteoarthritis. Thus the prevalence of osteoarthritis could have been reported as $67 \%$ or $21 \%$ depending on the diagnostic criterion used. Only two of the 24 knee joints were abnormal on radiography, one of which was thought to have changes due to osteoarthritis (4\%). Large osteophytes and areas of eburnation, particularly if on the patella groove of the femur or the anteroposterior aspects of the tibio- femoral joint, were often invisible in the radiograph. This suggests that radiography is a poor method of detecting osteoarthritis. It may also partly explain the discrepancy between changes seen in radiographs and symptoms found in epidemiological studies and the difficulties of developing diagnostic criteria for osteoarthritis of the knee. ${ }^{5}$ Areas of osteophytosis or focal osteoarthritis may cause symptoms or functional problems but remain invisible to clinicians or radiologists.

1 Rogers J, Waldron T, Dieppe PA, Watt I. Arthropathies in paleopathology: the basis of classification according to most probable causes. Fournal of Archaeobasis of classification according

2 Kellgren JH, Lawrence JS. Radiological assessment of osteoarthritis. Ann Rheum Dis 1957;16:494-502.

3 Rogers J, Watt I, Dieppe P. Arthritis in Saxon and mediaeval skeletons. BrMed f 1981;283:1668-71.

4 Clarke GA, Delmond JA. Vertebral osteophytosis in Dickson mound populations: a biomechanical interpretation. Henry Ford Hosp Med f 1979;27:48-54. 5 McAlindon T, Dieppe PA. Osteoarthritis: definitions and criteria [Editorial] Ann Rheum Dis 1989;48:531-2.

(Accepted 9 November 1989)

\title{
Effect of non-steroidal anti-inflammatory drugs on dyspeptic symptoms
}

\section{T M Shallcross, R V Heatley}

Department of Medicine, St James's University Hospital, Leeds LS9 7TF T M Shallcross, MRCP, research fellow

R V Heatley, FRCP, senior lecturer in medicine

Correspondence to: Dr Shallcross.

$\operatorname{Br} \operatorname{Med} \mathcal{f} 1990 ; 300: 368-9$
The association of non-steroidal anti-inflammatory drugs with the lifethreatening complications of peptic ulceration is well documented.' Elderly patients with peptic ulceration are less likely to complain of dyspepsia if they are using these drugs. ${ }^{2}$ As dyspeptic symptoms are a major indication for gastroscopy we investigated whether their diagnostic importance may be altered in patients taking non-steroidal anti-inflammatory drugs, which could lead to delay in the diagnosis of peptic ulceration.

\section{Patients, methods, and results}

We studied 149 consecutive patients with dyspepsia referred to an open access endoscopy clinic by rheumatologists $(22 \%)$ and general practitioners. Before endoscopy patients were interviewed with a structured questionnaire about their symptoms and use of non-steroidal anti-inflammatory drugs. Dyspepsia was broadly defined as pain, discomfort, or burning in the middle or upper part of the stomach or the lower chest, and patients who had angina were excluded. Statistical analysis was by the $\chi^{2}$ test with Yates's correction. The ratio of the prevalence of a symptom in patients with ulcers to the prevalence in those without ulcers was used to indicate the diagnostic importance of the symptom (table).

Fifty patients had taken non-steroidal anti-inflammatory drugs regularly during the month before endoscopy. Forty eight patients had peptic ulcers (seven oesophageal, 18 gastric, 21 duodenal, and two gastric and duodenal). Among the patients who had not taken non-steroidal anti-inflammatory drugs pain that woke them at night was significantly more common in those with ulcers $(67 \% v 29 \%, \mathrm{p}=0.003)$, whereas among those who took non-steroidal antiinflammatory drugs this symptom was less common in those with ulcers ( $38 \% v 46 \%)$; the difference between the two groups with ulcers was also significant $(p=0 \cdot 041)$. Localised epigastric pain was not significantly associated with ulceration in those who had not used non-steroidal anti-inflammatory drugs $(30 \% v$ $20 \%$ ) but showed a significant negative association with peptic ulcer in the group who had used these drugs $(14 \% v 58 \%, \mathrm{p}=0.004)$. Among the patients without ulceration localised epigastric pain was significantly more common in those taking non-steroidal antiinflammatory drugs $(58 \% v 20 \%, \mathrm{p}=0 \cdot 004)$. Considerable differences in the diagnostic implications of other symptoms were seen. In particular, pain occurring before meals or when the patient was hungry and loss of $\geqslant 3 \mathrm{~kg}$ in weight during the past six months showed a positive association with ulcers in those who had not taken non-steroidal anti-inflammatory drugs but a 

patients who had not taken non-steroidal anti-inflammatory drugs and those who had

\begin{tabular}{|c|c|c|c|c|c|c|}
\hline \multirow[b]{2}{*}{ Symptom } & \multicolumn{3}{|c|}{$\begin{array}{l}\text { Had not taken non-steroidal } \\
\text { anti-inflammatory drugs }\end{array}$} & \multicolumn{3}{|c|}{$\begin{array}{l}\text { Had taken non-steroidal } \\
\text { anti-inflammatory drugs }\end{array}$} \\
\hline & No ulcer & Ulcer & Ratio & No ulcer & Ulcer & Ratio \\
\hline Pain that woke patient at night & $22 / 75(29)^{\star}$ & $16 / 24(67) \dagger$ & $2 \cdot 3$ & $12 / 26(46)$ & $9 / 24(38)$ & 0.83 \\
\hline Localised epigastric pain & $14 / 69(20)$ & $7 / 23(30)$ & 1.5 & $11 / 19(58) \ddagger$ & $2 / 14(14)$ & $0 \cdot 24$ \\
\hline Pain before meals or when hungry & $23 / 75(31)$ & $10 / 24(42)$ & $1 \cdot 4$ & $7 / 26(27)$ & $6 / 24(25)$ & 0.93 \\
\hline Weight loss ( $\geqslant 3 \mathrm{~kg}$ in 6 months) & $12 / 69(17)$ & $8 / 23(35)$ & $2 \cdot 1$ & $5 / 19(26)$ & $3 / 14(21)$ & 0.81 \\
\hline History of dyspepsia $>2$ years & $39 / 75(52)$ & $9 / 24(38)$ & $0 \cdot 73$ & $7 / 26(27)$ & $19 / 24(42)$ & 1.6 \\
\hline Food sticking on way to stomach & $6 / 69(9)$ & $5 / 23(22)$ & $2 \cdot 4$ & $5 / 19(26)$ & $4 / 14(29)$ & $1 \cdot 1$ \\
\hline Vomiting with pain & $6 / 69(9)$ & $5 / 23(22)$ & $2 \cdot 4$ & $0 / 19$ & $1 / 14(7)$ & - \\
\hline Smoker $(>10$ cigarettes/week $)$ & $27 / 75(36)$ & $14 / 24(58)$ & 1.6 & $9 / 26(35)$ & $10 / 24(42)$ & $1 \cdot 2$ \\
\hline Pain made worse by food & $29 / 75(39)$ & $11 / 24(48)$ & $1 \cdot 2$ & $12 / 26(46)$ & $13 / 24(54)$ & $1 \cdot 1$ \\
\hline Pain relieved by food or antacid & $44 / 75(59)$ & $16 / 24(67)$ & $1 \cdot 1$ & $19 / 26(73)$ & $19 / 24(79)$ & $1 \cdot 1$ \\
\hline Episodic pain & $41 / 75(55)$ & $13 / 24(54)$ & 0.98 & $18 / 26(69)$ & $14 / 24(58)$ & 0.84 \\
\hline $\begin{array}{l}\text { Pain began after use of non-steroidal } \\
\text { anti-inflammatory drugs }\end{array}$ & & & & $18 / 26(69)$ & $17 / 24(71)$ & $1 \cdot 0$ \\
\hline Mean (range) age (years) & \multirow{2}{*}{\multicolumn{3}{|c|}{$\begin{array}{cc}43 \cdot 8(15-81) & 50 \cdot 7(26-75) \\
3 & 2\end{array}$}} & \multirow{2}{*}{\multicolumn{3}{|c|}{$\begin{array}{cc}57 \cdot 8(23-80) & 59 \cdot 6(24-82) \\
12 & 9\end{array}$}} \\
\hline No with rheumatoid arthritis & & & & & & \\
\hline
\end{tabular}

${ }^{\star} \mathrm{p}=0.003$ Compared with patients with ulcer who had not taken non-steroidal anti-inflammatory drugs. $t p=0.041$ Compared with patients with ulcer who had taken non-steroidal anti-inflammatory drugs $\neq \mathrm{p}=0.004$ Compared with patients with ulcer who had taken non-steroidal anti-inflammatory drugs and those without ulcer who had not taken non-steroidal anti-inflammatory drugs.

negative association with ulceration in those who had taken them. A history of dyspepsia of over two years was negatively associated with peptic ulcers in patients who had not taken non-steroidal anti-inflammatory drugs but positively associated with ulceration in those who had.

\section{Comment}

As well as contributing to the complications of peptic ulceration non-steroidal anti-inflammatory drugs seem to alter the profile of symptoms that would otherwise alert clinicians to the need for further investigation. Scoring systems have been suggested as a method of improving the cost effectiveness of endoscopy services, ${ }^{3}$ and detailed studies have highlighted symptoms likely to be associated with important underlying disease. ${ }^{+}$We suggest that dyspeptic symptoms are an unreliable indication of peptic ulceration in patients using non-steroidal anti-inflammatory drugs. From our evidence all patients taking non-steroidal anti-inflammatory drugs must be assumed to be at risk of developing peptic ulceration, with the consequent risk of bleeding or perforation, irrespective of either the presence of or the characteristics of dyspepsia. Non-steroidal anti-inflammatory drugs should be avoided whenever possible, but when this is not feasible we would recommend investigation by endoscopy or barium meal examination even for seemingly trivial dyspeptic symptoms.

This work was supported by a grant from Smith, Kline and French Ltd. We thank the many general practitioners who referred patients to take part in this study and Dr M R Martin for allowing us to study patients under his care.

1 Sommerville K, Faulkner G, Langman M. Non-steroidal anti-inflammatory drugs and bleeding peptic ulcer. Lancet 1986;i:462-4.

2 Skander MP, Ryan FP. Non-steroidal anti-inflammatory drugs and pain free peptic ulceration in the elderly. BrMed $\mathcal{F}$ 1988;297:833-4.

3 Mann J, Holdstock G, Harman M, Machin D, Loehry CA. Scoring system to improve cost effectiveness of open access endoscopy. Br Med $\mathcal{J} 1983 ; 287$ 937-40.

4 Horrocks JC, De Dombal FT. Clinical presentation of patients with 'dyspepsia.' Detailed symptomatic study of 360 patients. (iut 1978;19:19-26.

Accepted 30 October 1989

\section{Restoration of perception of hypoglycaemia after hemiparesis in an insulin dependent diabetic patient}

\section{Alastair C H Pell, Brian M Frier}

Diabetic Department, Royal Infirmary of Edinburgh, Edinburgh EH3 9YW

Alastair C H Pell, MRCP, registrar

Brian M Frier, MD, consultant physician

Correspondence to: $\mathrm{Dr}$ Frier.

Br Med f 1990;300:369-70
Acute hypoglycaemia can provoke neurological deficit of varying severity and duration. Many patients who have had insulin dependent diabetes for a long time lose their perception of the autonomic warning symptoms of hypoglycaemia and become more vulnerable to severe neuroglycopenia. We report on a diabetic patient who could not detect the signs of hypoglycaemia, and had a stroke during a severe episode. He subsequently was able to recognise the onset of hypoglycaemia by the transient development of reproducible neurological signs.

\section{Case report}

A 49 year old man who had had insulin dependent diabetes for 31 years developed severe hypoglycaemia and was comatose for two hours. His blood glucose concentration on admission was $1.2 \mathrm{mmol} / \mathrm{l}$ (by autoanalyser), and he recovered consciousness after administration of intravenous glucose. Examination showed a right sided hemiparesis which resolved gradually over the next month, leaving him with hyperreflexia on the right side. No vascular cause was found for the hemiparesis, and investigations, which included computed tomography of the brain, yielded normal results.

His diabetes had been treated with a combination of short and intermediate acting insulins twice a day. $\mathrm{He}$ had never achieved optimal glycaemic control, and his total glycated haemoglobin concentration was $10.4 \%$ (normal range 5-8\%) on admission. During the preceding year he had lost the ability to recognise the autonomic warning symptoms of hypoglycaemia and had required treatment for hypoglycaemic coma on three previous occasions, but had not sustained any neurological deficit. He did not have a history of cerebrovascular or cardiac disease or transient ischaemic attacks and did not have complications of diabetes apart from background diabetic retinopathy.

After the stroke he experienced further hypoglycaemia without losing consciousness and continued to be unable to recognise the autonomic warning symptoms. He observed, however, that he consistently developed weakness and incoordination of the right side when his blood glucose concentration fell below $2.0 \mathrm{mmol} / \mathrm{l}$ and that this resolved after he took glucose. He was able to rely on these signs to warn him about hypoglycaemic episodes, which occurred monthly, and prompt him to take glucose, thus preventing progression to more severe hypoglycaemia.

\section{Comment}

Transient hemiparesis is a recognised and alarming manifestation of acute hypoglycaemia, although complete resolution of symptoms usually occurs when the hypoglycaemia is corrected. ${ }^{1-3}$ This severe manifestation of neuroglycopenia is more common in older insulin treated patients with coexisting cerebrovascular disease and may cause a temporary exacerbation of preexisting hemiparesis. ${ }^{2}$ It has been suggested that the major haemodynamic and haemostatic changes associated with severe hypoglycaemia could precipitate an acute vascular event, ${ }^{+}$and in our patient the initia neurological damage was sustained during severe hypoglycaemia. Although cerebral blood flow is 